\title{
REINFORCED SUBBASES AND APPLICATION OF OTHER CHOSEN PARAMETERS IN SLEEPER SUBGRADE DIMENSIONING
}

The paper focuses on reinforced subbases which are frequently applied to modernised railway tracks of Slovak Railways (ŽSR) despite certain theoretical and normative deficiencies. Based on the evaluation of laboratory measurements other parameters which are to be taken into consideration when dimensioning a sleeper subgrade construction are specified.

\section{Introduction}

Integration of the Slovak Republic into the EU makes new, higher demands on the railway transport and it is inevitable to accept them. Besides this, when modernising the railway infrastructure of Slovak Railways (ŽSR), it is necessary to respect required parameters based on European Agreement on Main International Railway Lines (AGC) and European Agreement on Important International Combined Transport Lines and Related Installations (AGTC). Implementation of these agreements is obligatory on $916 \mathrm{~km}$ (4 corridor localities) out of $3662 \mathrm{~km}$ of the Slovak railway tracks. Modernisation of the railway tracks improves their technical parameters, namely the adaptation of directional conditions to $160 \mathrm{~km} \cdot \mathrm{h}^{-1}$ and the adaptation of the railway substructure to the axle force of $225 \mathrm{kN}$. At the same time new modern materials, components and technologies are applied, which is represented mainly by the use of geosynthetics in the railway substructure construction. Its application depends on its function in the sleeper subgrade (isolating, filter, reinforcing, draining, protective or tightening).

Geosynthetics has been applied into a large number of modernised railway corridor localities and approximately $80 \mathrm{~km}$ of the modernized railway tracks have been put into operation. Regarding the qualities which geosynthetics offers in the railway substructure, mainly the geosynthetics with the reinforcing function suffers from the insufficient normative basis for dimensioning of reinforced construction layers (with respect to its characteristics and characteristics of its geological surroundings).

\section{Design of reinforced subbases in railway substructure - current state}

The required deformation resistance of the sleeper subgrade construction (detected by a static plate loading test - SPLT) and protection of the subgrade surface against the influence of frost are two main indicators which determine the required subbase thickness on the subgrade consisting of fine-grained soil (Fig. 1). The assumed value of the static deformation module of the subgrade surface $E_{0}$ and the required value of the static deformation module on the level of the railway substructure $E_{e k v}$ are in accordance with the methodology given in [1] the required input parameters for the subbase design (i.e. design of construction structure, type of applied material and its dimensions). These values are determined in a relevant railway technical standard depending on a speed zone (1-5). In the case that the assumed value of the static deformation module of the subgrade surface reaches lower values than required, it is possible to use several solutions how not only to increase the deformation resistance, but reach the required value $E_{e k v}$ on the level of the railway substructure, as well. One of possibilities is to design a sleeper subgrade construction No. 3 sleeper subgrade with subbase reinforced by geosynthetics. When applying this solution, a choice of suitable reinforcing geosynthetics and suitable material (aggregate) of the subbase would follow. At present, in accordance with the requirements given by Slovak Railways Authorities, it is possible to use only such geosynthetics which is authorized by Slovak Railways on the basis of accredited tests realized in testing laboratories, in situ or, if it was authorized according to the Regulation No. 61/1999. However, the certificate issued by Slovak Railways does not declare the reinforcing effect of geosynthetics for example by TBR parameter (Traffic Benefit Ratio) or BCR parameter (Base Course Reduction Ratio); it is based only on the reached value of the static deformation modules from SPLT, although (as it will be proved hereinafter) SPLT cannot sufficiently evaluate the efficiency of reinforcing geosynthetics [2], [3]. After the selection of proper reinforcing geosynthetics it is possible to proceed in dimensioning of the reinforced subbases as follows:

- respecting the results of particular geosynthetics given by a producer (distributor), or based on the certificate issued by Slovak Railways the required thickness of the reinforced subbase is determined for particular conditions of the subgrade surface deformation resistance;

\footnotetext{
* Libor Ǐ̌volt, Ján Kardoš, Martin Mečár

Department of Railway Engineering and Track Management, Faculty of Civil Engineering, University of Žilina, Slovakia,

E-mail: libori@fstav.uniza.sk,jan_kardos@vahostav-sk.sk, mecar@fstav.uniza.sk
} 


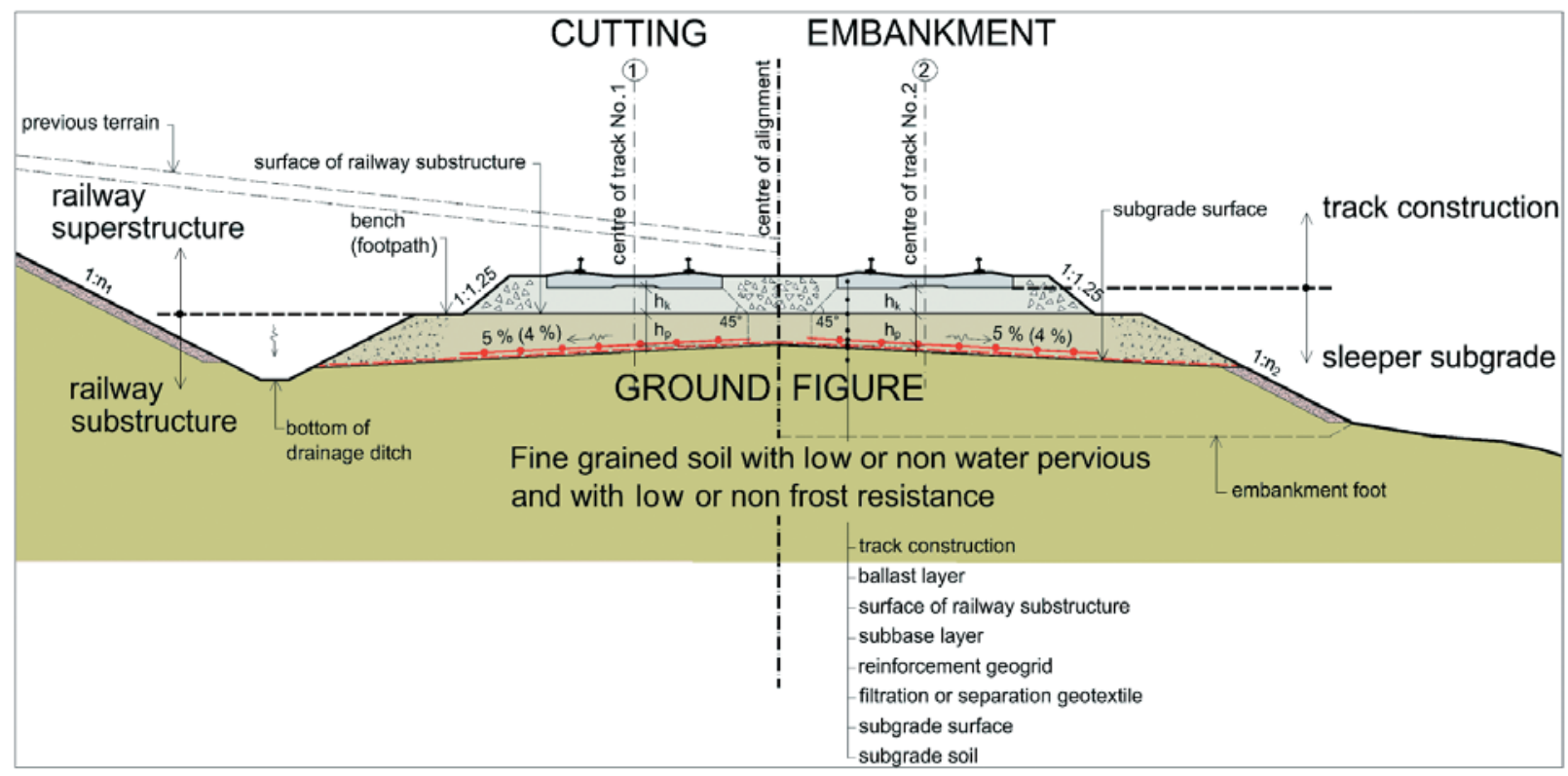

Fig. 1 Front view of double track - sleeper subgrade type No. 3

- according to the regulation [1] DORNII method may be used, and in the case that the subbase reinforced by stiff biaxial geogrids is designed, it is possible to use the deformation module value of the reinforced subbase $E_{i}=80-140 \mathrm{MPa}$,

- again, according to the regulation [1] DORNII method may be used, when the unreinforced subbase is designed at first, and it is subsequently reduced with Deutsche Bahn AG or Czech Railways $(\check{C} D)$ dimensioning method in the following way:

- $\mathrm{DB} A \mathrm{AG}$ - if the subbase thickness is more than $0.50 \mathrm{~m}$ and at the same time, if the deformation module of the subgrade surface $E_{0}$ is $10-30 \mathrm{MPa}$ (from SPLT according to DB), the subbase thickness may be reduced in $0.10 \mathrm{~m}(B C R \leq 20 \%)$ [4],

- $\check{C}$ - if reinforcing geosynthetics in the gravel subbase is used, the subbase thickness may be reduced in $25 \%(B C R \leq 25 \%)$ and in the case of the crushed rock subbase in $30 \%$ ( $B C R \leq$ $\leq 30 \%)[5]$.

When dimensioning the reinforced subbase according to all the above mentioned methods, the result is a construction with an unknown value of $T B R$ and consequently with an unknown durability or economic return. This situation is caused by inadequately specified conditions for issuing the certificates which further follow from the insufficient normative basis for the reinforced subbase diagnostics. Research on the reinforced subbases that has been already done shows the necessity of using a diagnostic device with cyclic loading (stationary, non-stationary) for diagnostics of these constructions. The reason is that it simulates transport loading more reliably because the reinforcing effect of any geosynthetics is connected with an accumulation of permanent deformations emerging from the compaction of the subbase material (this applies mainly to geogrids).
Despite the above mentioned arguments the certificates have continuously been accepted due to the insufficient normative basis at Slovak Railways. These certificates are based only on the results obtained by SPLT and their evaluation for each particular use of the aggregate and quality of its compaction. The results of many measurements on the railway substructure models and in situ measurements realized by the Accredited laboratory of the Department of Railway Engineering and Track Management (AL DRETM) served as a basis for the certificates issued to distributors and producers of reinforcing geosynthetics. Since 1998 ca 267 constructions have been diagnosed in situ and 217 in the laboratory which represents ca 484 realized and evaluated static plate loading tests.

\section{Analysis of experimental research results on reinforced subbases}

Description of the subgrade surface model and methods of laboratory measurements are given in [6]. This paper presents the analysis and evaluation of the measurements with the focus on the methodology of the reinforced subbase dimensioning and the importance of the compaction degree on the overall deformation resistance of the sleeper subgrade construction.

In 2006 several measurements of the biaxial stiff welded geogrid efficiency were realized in the Accredited laboratory of DRETM (with various deformation resistance of the subgrade surface - ca $5,10,15,20$ and $25 \mathrm{MPa}$ ) which finally served as a basis for issuing the certificate for the tested type of geogrid and designed structure and dimensions of the reinforced construction layers in the railway substructure. The comparative measurements on constructions without the applied geogrid were carried out in order to prove the efficiency of the applied tested geogrid. The results of 
the measurements realized on the reinforced and unreinforced construction with the equivalent deformation module of the subgrade surface $E_{0}=$ ca $5.0 \mathrm{MPa}$ (where the maximum reinforcing efficiency of the applied geogrid was assumed) will be analyzed and evaluated in the following text. The structure of the compared sleeper subgrade constructions is shown in Tab. 1.

The static plate loading tests were successively realized on particular subbase construction thicknesses of $0.30 \mathrm{~m}, 0.50 \mathrm{~m}$ a $0.70 \mathrm{~m}$. The compared construction was identical regarding material and geometry, only the reinforcing geogrid was not applied in it. The material of the subgrade surface was classified as sandy clay and the equivalent deformation module of the subgrade surface $E_{0}=$ ca 5.0 MPa was obtained when water content $\mathrm{w}$ reached ca $23.5 \%$. Crushed rock with the fraction of $0 / 63 \mathrm{~mm}$ was applied into the subbase (its technical parameters are shown in Tab. 2. Technical parameters of the built-in reinforcing geogrid are shown in Tab. 3. The ratio between efficient fraction calibre of $d_{50}$ and the size of the geogrid aperture is 3.12 or 3.20 , which presupposes an efficient concurrence between the aggregate and geogrid. The disadvantage of the applied geogrids is the height of the tensile element which reaches the values of 0.80 , or $0.95 \mathrm{~mm}$ depending on the applied geogrid. Based on a known theoretical assumption, this fact may cause a small crushing resistance (during interlocking of aggregate particles and geogrid) and thus reduce compactness between the geogrid and aggregate. Another disadvantage of the components applied in the tested construction is a small ratio value between the surface area of the geogrid and the surface area of the geogrid apertures $(75.7-77.4 \%$ ), which is caused by wide tensile elements of the geogrid $(6-8 \mathrm{~mm})$. This fact may cause the insufficient penetration of the aggregate into the geogrid apertures and may result in forming of a slip surface on the geogrid level.

There were 72 SPLTs realized in 2 cycles of measurement in order to evaluate the effect of the geogrid built in the construction layers of the railway substructure (so called reinforced subbase of the sleeper subgrade). There were 6 SPLTs realized on each partial layer of the subbase and after the realization of SPLTs and the compaction of crushed rock on the last two construction layers, another 3 SPLTs were realized. The influence of the compaction degree on the deformation resistance of the reinforced/unreinforced construction was tested in this way. The summary of the results
Structure of the compared constructions

Table 1

\begin{tabular}{|l|l|}
\hline Construction I - reinforced & Construction II - unreinforced \\
\hline - subgrade surface with the & - subgrade surface with the \\
equivalent deformation module & equivalent deformation module \\
$E_{0}=$ ca $5.0 \mathrm{MPa}$ & $E_{0}=$ ca $5.0 \mathrm{MPa}$ \\
\hline - filtration geotextile & - filtration geotextile \\
\hline - geogrid GG - A & - - \\
\hline - crushed rock with the fraction & - crushed rock with the fraction \\
$0 / 63 \mathrm{~mm}$ and thickness $0.30 \mathrm{~m}$ & $0 / 63 \mathrm{~mm}$ and thickness $0.30 \mathrm{~m}$ \\
\hline - geogrid GG - B & - \\
\hline - crushed rock with the fraction & - crushed rock with the fraction \\
$0 / 63 \mathrm{~mm}$ and thickness $0.40 \mathrm{~m}$ & $0 / 63 \mathrm{~mm}$ and thickness $0.40 \mathrm{~m}$ \\
\hline
\end{tabular}

Technical parameters of the applied geogrids

Table 3

\begin{tabular}{|c|c|c|}
\hline Type of geogrid / Characteristics & GG - A & GG - B \\
\hline Tensile strength $\left(\mathrm{kN} \cdot \mathrm{m}^{-1}\right)$ & 34 & 25 \\
\hline Strength during $2 \%$ elongation $\left(\mathrm{kN} \cdot \mathrm{m}^{-1}\right)$ & 11 & 8 \\
\hline Strength during $5 \%$ elongation $\left(\mathrm{kN} \cdot \mathrm{m}^{-1}\right)$ & 23 & 17 \\
\hline Strain at maximum load (\%) & 10 & 10 \\
\hline Type of polymer & \multicolumn{2}{|c|}{ polypropylene } \\
\hline Type of geogrid & \multicolumn{2}{|c|}{$\begin{array}{l}\text { stiff biaxial geogrid of the } \\
\text { extruded straps connected by } \\
\text { laser welding }\end{array}$} \\
\hline Mesh size A x B (mm) & $44 \times 43$ & $44 \times 44$ \\
\hline Height and width of the rib (mm) & $0.95 \times 7.0$ & $0.80 \times 6.0$ \\
\hline Open area to overall area (\%) & $75.7 \%$ & $77.4 \%$ \\
\hline
\end{tabular}

obtained by testing the reinforced and unreinforced construction (average values of deformation resistance and compaction degree) is shown in Tab. 4 and its graphic representation in Fig. 2.

Table 4. and the diagram of the deformation module of the reinforced and unreinforced construction show that small differences between the compared constructions occurred in real thickness, the acquired compaction degree of the subbase, and modelling of the deformation resistance of the subgrade surface. Despite the

Technical parameters of the compared constructions

Table 2

\begin{tabular}{|c|c|c|c|c|c|}
\hline \multicolumn{2}{|c|}{ Effective grain size $\mathrm{dx}(\mathrm{mm})$} & \multicolumn{2}{|c|}{ Fraction ratio $(\%)$} & \multicolumn{2}{|c|}{ Further characteristics } \\
\hline$d_{10}$ & 0.445 & $f$ & 4.919 & Number of uneven granularity $C_{U}$ & 42.182 \\
\hline$d_{30}$ & 5.062 & $s$ & 14.134 & Number of curvature $C_{C}$ & 3.074 \\
\hline$d_{50}$ & 13.779 & $g$ & 78.508 & Water content $w(\%)$ & 3.560 \\
\hline$d_{60}$ & 18.751 & $c b$ & 2.439 & Wash-off particles $b(\%)$ & 4.489 \\
\hline$d_{100}$ & 64.281 & $b$ & 0.000 & Filtration coefficient $k_{f}\left(\mathrm{~m} \cdot \mathrm{s}^{-1}\right)$ & 0.01742 \\
\hline \multirow{2}{*}{\multicolumn{4}{|c|}{ Classification of subbase material according to USCS: }} & Maximum density $\rho_{\max }\left(\mathrm{kg} \cdot \mathrm{m}^{-3}\right)$ & 2130 \\
\hline & & & & Minimum density $\rho_{\min }\left(\mathrm{kg} \cdot \mathrm{m}^{-3}\right)$ & 1440 \\
\hline
\end{tabular}


Resulting average values of the tested parameters on the reinforced and unreinforced construction

Table 4

\begin{tabular}{|c|c|c|c|c|c|c|c|c|c|}
\hline \multicolumn{2}{|r|}{ Testing construction } & \multicolumn{4}{|c|}{ Construction I - reinforced } & \multicolumn{4}{|c|}{ Construction II - unreinforced } \\
\hline & & \multirow{2}{*}{$\begin{array}{c}\begin{array}{c}E_{e k v} \\
(\mathrm{MPa})\end{array} \\
4.64\end{array}$} & \multirow{2}{*}{$\begin{array}{c}M_{z} \\
\\
2.24\end{array}$} & \multirow{2}{*}{\begin{tabular}{|c|}
$\begin{array}{c}\text { Real } \\
\text { thic-kness } \\
\text { of subbase } \\
(\mathrm{m})\end{array}$ \\
- \\
\end{tabular}} & \multirow{2}{*}{$\begin{array}{c}\begin{array}{c}\text { Day of } \\
\text { measuring }\end{array} \\
0 \\
\end{array}$} & \multirow{2}{*}{$\begin{array}{c}\begin{array}{c}E_{e k v} \\
(\mathrm{MPa})\end{array} \\
4.99\end{array}$} & \multirow{2}{*}{$\begin{array}{c}M_{z} \\
\\
3.06 \\
\end{array}$} & \multirow{2}{*}{\begin{tabular}{|c|}
$\begin{array}{c}\text { Real } \\
\text { thic-kness } \\
\text { of subbase } \\
(\mathrm{m})\end{array}$ \\
- \\
\end{tabular}} & \multirow{2}{*}{$\begin{array}{c}\begin{array}{c}\text { Day of } \\
\text { measuring }\end{array} \\
0\end{array}$} \\
\hline \multirow{7}{*}{ 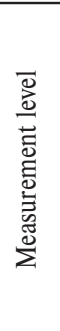 } & Subgrade surface before testing cycle & & & & & & & & \\
\hline & Subbase thickness $0.30 \mathrm{~m}$ & 16.04 & 2.08 & 0.291 & 6 & 19.72 & 2.13 & 0.287 & 14 \\
\hline & Subbase thickness $0.50 \mathrm{~m}$ & 35.04 & 1.93 & 0.489 & 8 & 43.28 & 1.93 & 0.517 & 22 \\
\hline & compacted & 43.83 & 1.63 & 0.488 & 9 & 56.97 & 1.56 & 0.516 & 26 \\
\hline & Subbase thickness $0.70 \mathrm{~m}$ & 49.30 & 1.63 & 0.690 & 9 & 60.38 & 1.92 & 0.692 & 31 \\
\hline & compacted & 67.06 & 1.58 & 0.688 & 10 & 70.74 & 1.62 & 0.690 & 33 \\
\hline & Subgrade surface after testing cycle & 5.52 & 2.70 & - & 15 & 8.27 & 2.11 & - & 36 \\
\hline
\end{tabular}

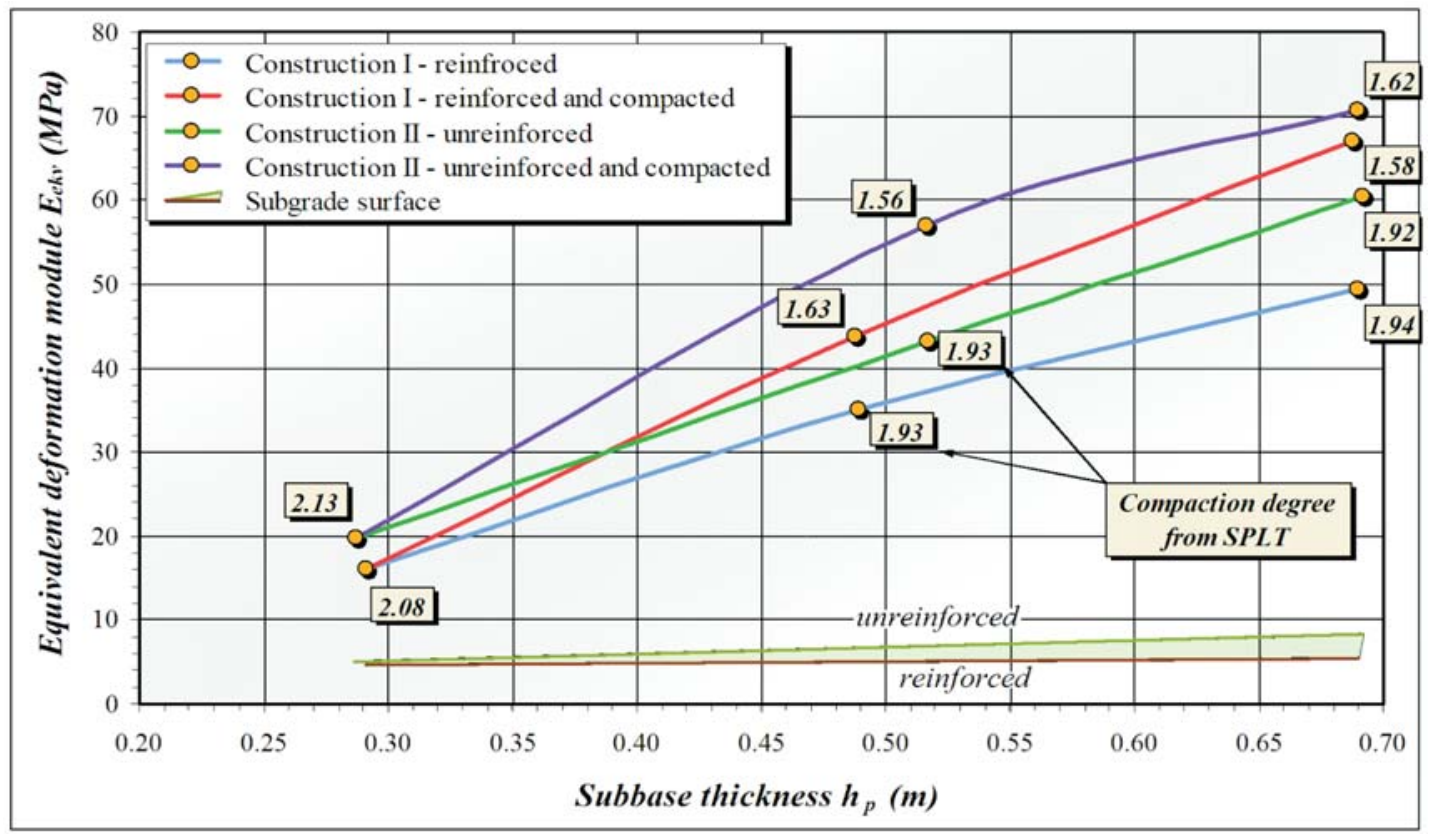

Fig. 2 The equivalent deformation module of the reinforced and unreinforced construction depending on the subbase thickness and compaction degree

effort put into the construction of two identical models, they were not completely identical. Duration of the experimental measurements presents a considerable problem when making a comparison, because it causes the increase of the deformation resistance of the subgrade surface on individual subbase layers during the measurement. The increase of the deformation resistance of the subgrade surface after the subbase removal is in the unreinforced construction 3.7 times higher than in the reinforced construction. This fact is caused by a longer period of the measurements on the construction in 21 days. Based on the above mentioned reasons, the results had to be further analysed in order to exclude these small differences and find a functional dependence between the following variables:

- the equivalent deformation module of the subgrade surface $E_{0}$ $(\mathrm{MPa})$ in the specific time of measurement of the equivalent deformation module on a particular construction layer $E_{e k v}$ (MPa),

- the equivalent deformation module on a particular construction layer $E_{e k v}(\mathrm{MPa})$,

- thickness of the subbase (reinforced/unreinforced) $h_{p}(\mathrm{~m})$,

- the acquired compaction degree $M_{z}$.

It was inevitable to reduce the number of four variables into two variables in order to obtain the required functional relation. The equivalent deformation module on a construction layer $E_{e k v}$ and the equivalent deformation module of the subgrade surface $E_{0}$ were replaced with a parameter of the equivalent deformation module increase $\Delta E_{e k v}$ which was determined from the equation:

$$
\Delta E_{e k v}=E_{e k v}-E_{0} \quad(\mathrm{MPa})
$$


The equivalent deformation module of the subgrade surface $E_{0}$ was determined with a linear interpolation from the deformation module values of the subgrade surface according to the time and location of the measurement on a particular construction layer and thus the deformation resistance increase of the subgrade surface during the measurement on a particular construction was taken into consideration, as well. The deformation module increase made it possible to remove a small difference between the deformation resistance of the subgrade surface on the reinforced and unreinforced construction, as well. Another assumption which had to be taken into consideration was connected with a linear relation between the equivalent deformation module increase $\Delta E_{e k}$ and thickness of the subbase $h_{p}$. A parameter which describes the given assumption is labelled as $k$ and is calculated according to the equation:

$$
k=\frac{\Delta E_{\text {ekv }}}{h_{p}} \quad\left(\mathrm{MN} \cdot \mathrm{m}^{-1}\right)
$$

There were two variables obtained through these procedures: the compaction degree $M_{z}$ and the parameter $k$. These variables may be easily analysed and it is possible to determine their functional relation from measured values with the method of regression and correlation analysis. There were 4 out of 24 pairs of the measured values excluded (the level of importance 0.95 ) on both the reinforced and unreinforced constructions. The graphic representation of regression and correlation analysis is shown in Fig. 3. Having used a simple regression function of an exponential form, the correlation coefficient reached the value $R=0.869$ for the reinforced and $R=0.889$ for the non-reinforced construction.

Having completed the obtained regression functions with the equations (1) and (2) the equations for the calculation of the equivalent deformation module $E_{e k v}$ or the required thickness of the subbase $h_{p}$ depending on the type of construction (reinforced/ unreinforced) and on the acquired compaction degree $M_{z}$ were derived. Equations applying to the reinforced construction are as follows:

$$
\begin{aligned}
& h_{p}=\frac{\left(E_{e k v}-E_{0}\right) \cdot M_{z}^{2.67}}{313}(\mathrm{~m}) ; \text { or } \\
& E_{e k v}=\frac{313 \cdot h_{p}}{M_{z}^{2.67}}+E_{0} \quad(\mathrm{MPa})
\end{aligned}
$$

Equations applying to the unreinforced construction are as follows:

$$
\begin{aligned}
& h_{p}=\frac{\left(E_{e k v}-E_{0}\right) \cdot M_{z}^{2.28}}{276}(\mathrm{~m}) ; \text { or } \\
& E_{e k v}=\frac{276 \cdot h_{p}}{M_{z}^{2.28}}+E_{0} \quad(\mathrm{MPa})
\end{aligned}
$$

When analysing the equations (3) and (4) it is obvious that the equivalent deformation module $E_{\text {ekv }}$ of the reinforced construction layer is always lower than that of the unreinforced construction. This phenomenon is probably caused by the insufficient interlocking of the aggregate into the geogrid apertures because the small height of the tensile elements (ribs) of the geogrid cannot activate the sufficient crushing resistance. At the same time the flat ribs probably cause that the aggregate particles lie on them and this does not prevent their movement; on the contrary, the flat ribs support the formation of a slip surface by lowering the friction between the geogrid and aggregate. [8]. The geogrid with flat tensile ribs may thus serve only as a membrane. Another fact that might impede the detection of reinforcing effect of the geogrid is the process of SPLT itself because it simulates the real loading only marginally. Since the current directives are based on the expected acquired equivalent deformation module from SPLT, it is neither appropriate nor possible to start with the reduction of the subbase thickness in this case (with the application of $B C R$ ) as it is mentioned in Chap. 2. When applying diagnostic devices with a more reliable simulation of the real operational loading (multiple cyclic loading) in the detection of the geosynthetics reinforcing effect, it will be possible to obtain parameters TBR depending on the type of the applied geosynthetics. At the same time it will be possible to specify the influence of various physical characteristics of geosynthetics and aggregate on their reinforcing effect in the subbase and thus, together with economic indicators, to design an optimum construction as for price and quality. Till then it is possible to reinforce the subbases only with the assumption of the coefficient $T B R$ increase, whose exact indicators are not known at present. It follows that the economic indicators of a particular geosynthetics application are unknown, as well.

The analysis of the equations (3) and (4) shows that the acquired compaction degree is a parameter which remarkably influences the final equivalent deformation module based on SPLT. The current dimensioning methodology [1] does not take into consideration the compaction degree but it uses another variable in calculation, namely a material deformation module of the construction layer $E_{i}$. Under certain circumstances the material deformation module of the construction layer $E_{i}$ may represent the material compactness because in the case of reaching a low deformation module, the material has the insufficient compaction (which means that it has a high compaction degree from SPLT). However, it is very difficult to measure the material deformation module and therefore its values are only estimated at certain intervals according to Tab. 5.9. given in [1]. On the contrary, the compaction degree based on SPLT characterizes properly the material conditions and the assumption of its future behaviour because the material compacted to a low compaction degree resists further loading with a lower deformation (decrease). One of the advantages of this method is a possibility of using measurement technique installed in the compaction machinery (vibratory rollers). They are able to monitor the decrease during compaction, evaluate the acquired compaction degree and thus determine the assumed deformation module on the construction layer indirectly. It is possible to use a dynamic plate loading test with a relative sensor of deflection for the evaluation of the compaction degree, as well. Its realization is easy and does not require much time [5]. Inclusion of the compaction degree into the dimensioning method would make it possible to design the construction thickness with regard to the compaction technology and to simplify diagnostics of a given construction, as well. 

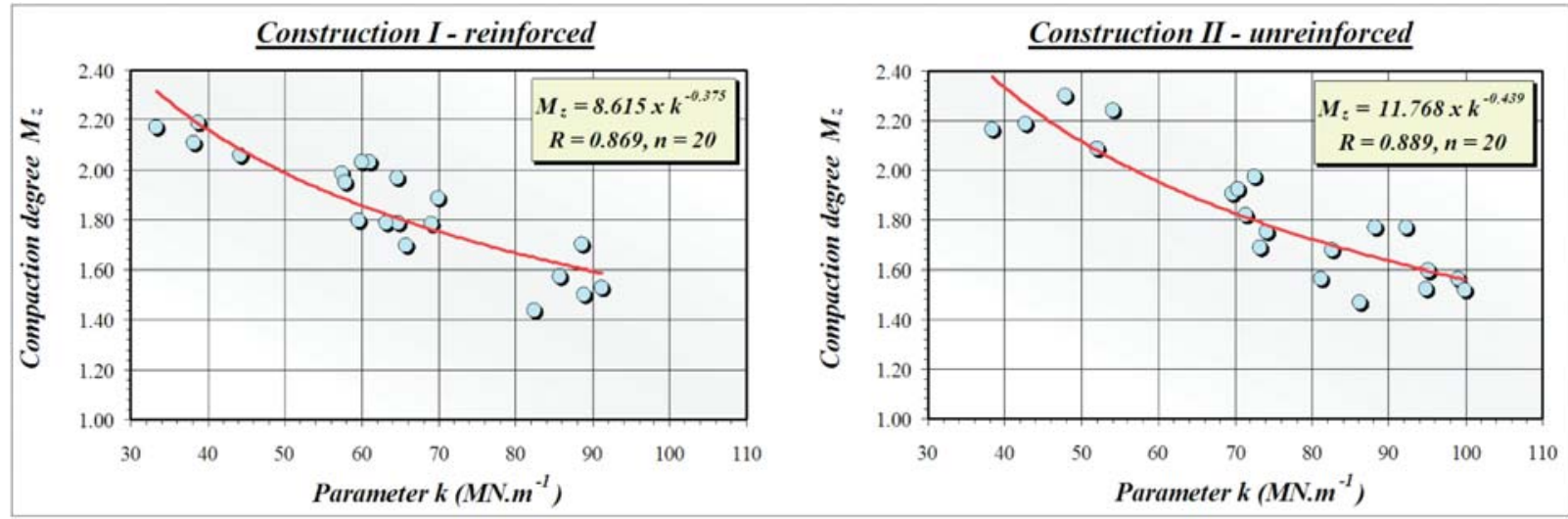

Fig. 3 Regression and correlation analysis of dependence between the compaction degree $M_{z}$ and the parameter $k$

Having transformed the equation (4) for the unreinforced construction into the graphic representation (Fig. 4) a dimensioning nomogram has been created. This nomogram may serve (when taking into consideration the required deformation module increase $\Delta E_{e k v}$ and the assumed compaction degree $M_{z}$ ) as a basis for determination of the required subbase thickness $h_{p}$, or on the contrary, for determination of the required compaction degree $M_{z}$ in a particular designed subbase thickness $h_{p}$. Validity of this dimensioning nomogram is for the subgrade surface with the equivalent deformation module $E_{0}=$ ca $5.0 \mathrm{MPa}$ (possibly for the range of $2.50 \mathrm{MPa}$
- 7.50 MPa). The graph (Fig. 4) shows an isoline determined by DORNII method according to [1] which presupposed the application of aggregate and the deformation module $E_{i}=80 \mathrm{MPa}$. It is possible to determine from the graph that the results of the calculation method are approximately identical with the experimental values for the acquired compaction degree $M_{z}=\mathrm{ca} 1.95$. If the required deformation module increase $\Delta E_{\text {ekv }}=40 \mathrm{MPa}$ and the assumed compaction degree $M_{z}=1.70$, it is possible to reduce the subbase thickness $\mathrm{hp}$ in $0.15 \mathrm{~m}=\mathrm{ca}$ in $40 \%$ (as the result of a higher compaction), as opposed to the calculation dimensioning

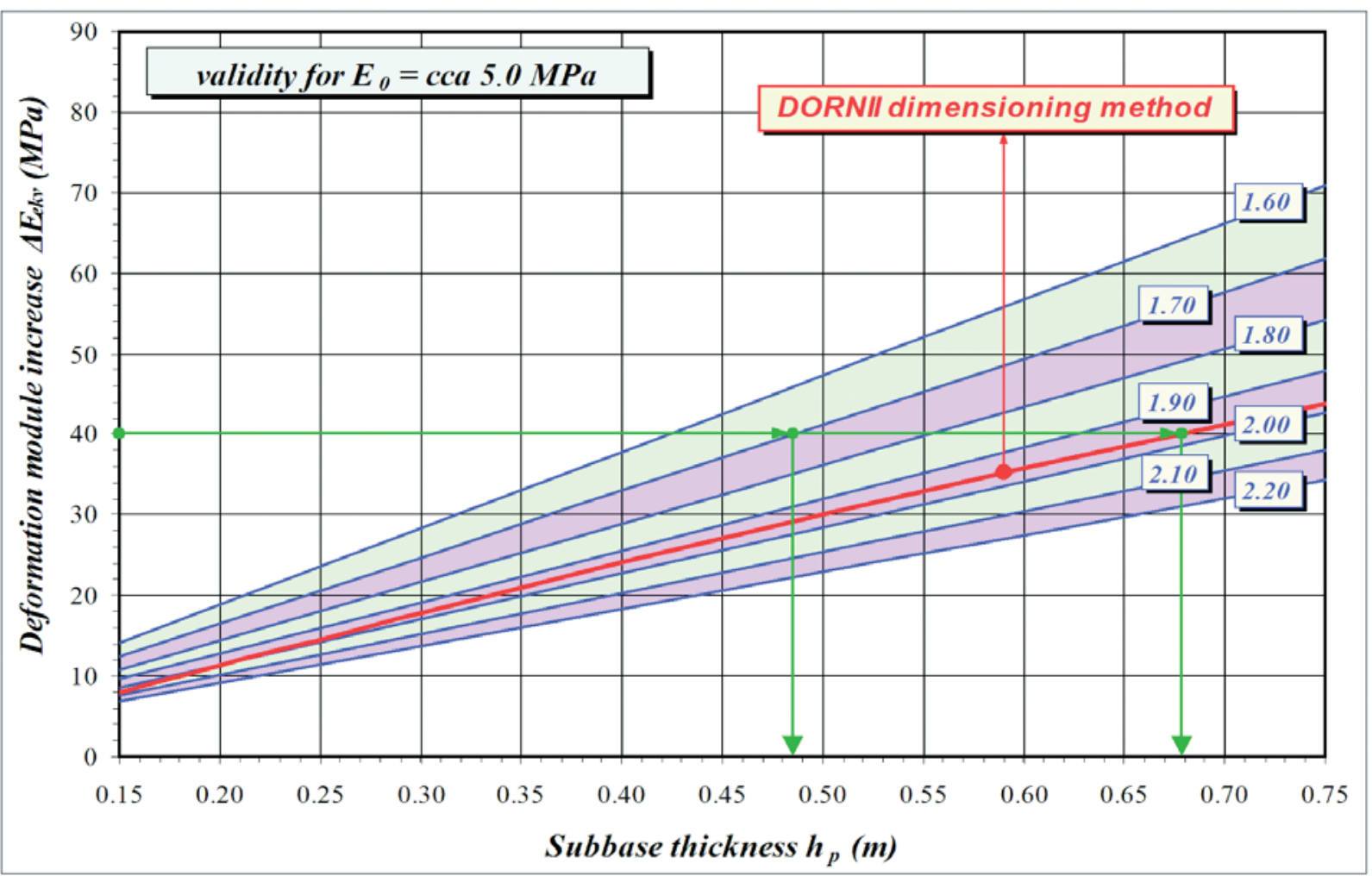

Fig. 4 Dimensioning nomogram for determination of the subbase thickness taking into consideration the compaction degree of the subbase material 
method. Evaluation of the experimental measurements in other values $E_{0}=10,15,20$ a $25 \mathrm{MPa}$ assumes that the above mentioned tendencies will be proved and it will be possible to develop a new dimensioning method which will be able to evaluate the influence of the compaction degree precisely. Based on the application of the specific aggregate (Tab. 1) it will be inevitable to verify the aggregate with a different fraction and granularity curve and to monitor its effect on the relation between the subbase thickness $\mathrm{hp}$ and the deformation module increase $\Delta E_{e k v}$, or to determine a possible degree of the effective compaction. It may be assumed that differences in granularity will not have a substantial influence on the equivalent module of deformation in a given compaction degree. However, according to the existing experience, granularity will be a significant factor for compactibility with regard to energy demands for the acquirement of the same compaction degree (density).

\section{Conclusion}

The process of design of the reinforced and unreinforced sub bases at Slovak railways has suffered many deficiencies. Reinforcement of subbases is based only on the unconfirmed assumption of the construction durability increase without its detailed quantification. After the evaluation of laboratory measurements it is obvious that the application of $B C R$ coefficients or determination of $T B R$ will be possible only after their determination on a given construction via cyclic loading tests. This is one of the reasons why the laboratory of DRETM plans to utilise an electro-hydraulic pulsator which is able to generate loading with variable frequency, variable deflection and thrust. Another step will be based on the necessity to establish a normative basis and conditions for issuing the certificates, which will apply these new possibilities of diagnostics in practice. It will be essential to monitor and determine the factors of the reinforcing geosynthetics and aggregate which influence their mutual efficiency in the subbase. Consequently, based on these factors a system for the evaluation of geosynthetics applicability will be developed with respect to particular conditions (deformation module of the subgrade surface, speed zone, type of aggregate, etc.).

The deformation resistance of the subbase is influenced mainly by the compaction degree which is very difficult to evaluate precisely by the current dimensioning methodology [1]. Based on the already obtained results and on the evaluation of further measurements realized at DRETM a new empirical dimensioning method covering further relevant factors is to be developed. Fig. 4 shows that current criteria for the maximum values of the acquired compaction degree from SPLT (for minimum compaction) are to be revised. It would put the current limit value of 2.20 closer to the value corresponding to DORNII method, i.e. 2.00 which would guarantee the fulfilment of the acquired deformation resistance in dimensioning calculation. At the same time it is important to realise that the influence of the acquired compaction degree on the acquired deformation resistance is increased together with the construction thickness. It follows that it is inevitable to determine not only general criteria for the compaction degree, but the criteria depending on the construction thickness, as well (bigger construction thickness $=$ stricter criteria for compaction degree).

The paper is a partial result of VEGA project No. 1/3336/06 Experimental analysis and verification of reliability of the traffic line multi-layer system.

\section{References:}

[1] Railway technical standard 736312 - Subbase construction layers designing, GR ŽSR, August 2005.

[2] IŽVOLT, L., KARDOŠ, J.: Reinforcing of sleeper subgrade construction layers, Expert opinion for PRODEX(r) spol. s r.o., Žilina, July 2006.

[3] GÖBEL, C., LIEBERENZ, K.: Handbuch Erdbauwerke, Der Bahnen, Eurailpress Tetzlaff-Hestra Gmbh\&Co.KG, 2004, ISBN 37771-0317-9.

[4] Instruction S4 of Czech Railways "Railway substructure".

[5] IŽVOLT, L., KARDOŠ, J., LELAK, J., MEČÁR, M.: Diagnostics of the track substructure model and its practical use, Communications - Scientific letters of the University of Zilina, Žilina, April 2005, ISSN 1335-4205.

[6] IŽVOLT, L., LELAK, J., KARDOŠ, J.: The results of the reinforced subbase layers laboratory tests, Theoretical Foundation of Civil Engineering, XV Russian-Slovak-Polish Seminar, Moscow-Rostov, September 2006, ISBN 83-908083-7-4.

[7] Instruction S4 of Slovak Railways "Railway substructure", NADAS, January 1988.

[8] IŽVOLT, L., KARDOŠ, J., LELAK, J.: Factors influencing efficiency of biaxial geogrid in subbase, Proc. IV International Conference GEOSYNTHETICS in Civil Engineering, Žilina, February 2007, ISBN 978-80-8070-646-3. 